\title{
Malnutrition screening in the elderly population
}

\author{
Dylan Harris MB MRCP ${ }^{1}$ Nadim Haboubi MD FRCP ${ }^{2}$
}

J R Soc Med 2005;98:411-414

Malnutrition is a state in which a deficiency, excess or imbalance of energy, protein and other nutrients causes adverse effects on body form, function and clinical outcome. ${ }^{1}$ To justify screening for this state in the elderly, four criteria must be satisfied: malnutrition must be a frequent cause of ill-health in this population; it must have a negative effect on outcomes; a simple, reliable, valid and acceptable screening test must be available to detect those who are malnourished or at risk of malnutrition; and there must be benefit from nutritional intervention in those identified by screening. In this review we consider whether these conditions are satisfied by tests of various kinds.

\section{WHAT IS THE EXTENT OF MALNUTRITION IN THE ELDERLY POPULATION?}

The above question is difficult to answer in the absence of universally accepted criteria to define malnutrition. ${ }^{2-7}$

In the older population, undernutrition rather than overnutrition is the main cause for concern, since its relation to morbidity and mortality is stronger than that of obesity. ${ }^{8}$ The prevalence of malnutrition increases with escalating frailty and physical dependence. ${ }^{1}$ The complex biological process of ageing is accompanied by many socioeconomic factors that also impact on nutritional status. ${ }^{9}$ Anorexia and weight loss are common in the elderly and the physiological decrease in appetite and food intake that accompanies normal ageing can be augmented by acute and chronic disease. ${ }^{10}$ Contributing factors are altered smell/ taste, poor dental health and age-related achlorhydria, in addition a decrease in physical activity leads to reduction of lean body mass and accumulation of body fat. ${ }^{4,10,11}$ Also important are social factors such as poverty and isolation, psychological factors such as depression and dementia, and medical factors such as poor visual acuity and prescribed medication. ${ }^{1,4,10,12}$ Many of these are reversible or responsive to treatment. ${ }^{10}$ In 2002 the Royal College of Physicians highlighted the over-65s as a nutritionally vulnerable group, with $12 \%$ of those living in the community at high or medium risk of malnutrition. The

Departments of ${ }^{1}$ Geriatric Medicine and ${ }^{2}$ Medicine, Nevill Hall Hospital, Abergavenny, South Wales NP7 7EG, UK

Correspondence to: Dr Dylan Harris

E-mail: dylangharris@hotmail.com prevalence was reckoned at 20\% among those in residential accommodation and up to $40 \%$ in those admitted to hospital. ${ }^{13}$ The College identified nutritional screening as an integral part of clinical practice.

The economic cost of preventable malnutrition to the National Health Service has been estimated at $£ 260$ million a year. ${ }^{14}$

\section{DOES MALNUTRITION HAVE A NEGATIVE EFFECT ON OUTCOME?}

There is ample evidence of the adverse consequences of malnutrition on physical and psychosocial outcomes, ${ }^{13,15-17}$ and seemingly these are independent of underlying disease and disability. ${ }^{18}$ Malnourished older people are at increased risk of falls, lengthy hospital stays and rehabilitation, institutionalization, postoperative complications, infections, pressure ulcers, poor wound healing, impaired muscle and respiratory function and death. $1,7,19$

\section{IS THERE A SUITABLE SCREENING TEST?}

Nutritional screening, in its various forms, looks for characteristics associated with nutritional problems so that the individuals identified can undergo full nutrition assessment and possible intervention. ${ }^{20}$

The process, as well as being quick and simple, needs to be acceptable to patients and healthcare workers. Furthermore, it must have good sensitivity for detecting treatable malnutrition, even if the specificity is lower. ${ }^{21,22}$ Ideally, a single nutritional marker would be consistently abnormal in patients with protein-energy malnutrition (high sensitivity), consistently normal in patients without proteinenergy malnutrition (high specificity), nutrition-specific (unaffected by non-nutritional factors), and made normal by nutritional support. ${ }^{23}$

\section{Body mass index (BMI)}

Body mass index (weight $[\mathrm{kg}] /$ height $\left[\mathrm{m}^{2}\right]$ ) predicts disease risk both in those termed underweight and in those who are obese. ${ }^{6}$ The World Health Organization categorizes underweight as BMI <18.5, normal 18.5-24.9, overweight 25-29.9, obese 30-39.9 and extreme obesity $>40$. However, BMI may be unreliable in the presence of confounding factors such as oedema or ascites, and may not identify significant unintentional weight loss if 
used as a single assessment. ${ }^{17,25,26}$ Furthermore, reliable measurement of height can be difficult in the elderly because of vertebral compression, loss of muscle tone and postural changes. ${ }^{17,27}$ For this reason, some screening tools use alternatives such as measurement of ulna length. ${ }^{8}$

\section{Anthropometry}

Skinfold thickness can be measured with standardized callipers but requires a skilled technique. Several different sites can be used-subscapular, supra-iliac, biceps, triceps, thigh, calf. The distribution of skinfold thickness varies with ageing and between sexes and between ethnic groups. ${ }^{23}$

Use of arm circumference depends on the assumption that the mass of the muscle group is proportional to its protein content and also reflects total body muscle mass. ${ }^{23}$ Midupper arm circumference is a helpful indicator of malnutrition applicable in ill patients (normal $23 \mathrm{~cm}$ males, $>22 \mathrm{~cm}$ females). ${ }^{28}$

Anthropometric indices are simple and inexpensive to obtain, ${ }^{29}$ but have to be interpreted in the light of age, gender and ethnicity. ${ }^{27}$ Furthermore, some are unreliable in conditions that cause limb oedema.

\section{Biochemical markers}

Serum proteins synthesized by the liver have been used as markers of nutrition - albumin, transferrin, retinol-binding protein and thyroxine-binding prealbumin. ${ }^{6}$ Of these, serum albumin has been most widely adopted because it predicts mortality and other outcomes (for example, perioperative complications) in older people. Nutritional state, however, is not the only factor affecting these proteins, others being inflammation and infection. This limits their usefulness, especially in the acutely ill. 5,6,16 In addition, the long half-life of albumin means that serum albumin does not respond to short-term changes in protein and energy intake. ${ }^{16}$ Transferrin is a more sensitive indicator of early protein-energy malnutrition but is unreliable in conditions including pregnancy, iron deficiency, hypoxaemia, chronic infection and hepatic disease. ${ }^{16}$ A low total lymphocyte count signifies a poor prognosis and is independent of low serum albumin. ${ }^{6,11}$ Malnutrition contributes to age-related immune dysregulation, including decreased lymphocyte proliferation. ${ }^{10} \mathrm{~A}$ low total cholesterol has also been correlated with risk of malnutrition ${ }^{3}$ and assessment of vitamin and trace element status is also important (including thiamine, riboflavin, pyridoxine, calcium, vitamin D, B12, folate and ferritin).

No biochemical marker on its own offers a satisfactory screening test. Their main value is in more detailed assessment (particularly risk stratification of patients

\section{Malnutrition screening tools}

In view of the limitations of individual methods, over fifty combinations have been tried, with different criteria, scoring systems, intended users, and acceptability. ${ }^{8}$ Below we discuss two that have been well validated.

The Malnutrition Universal Screening Tool (MUST) derives a score classifying malnutrition risk as low, medium or high on the basis of three components-BMI, history of unexplained weight loss and acute illness effect. ${ }^{8}$ MUST was developed primarily for use in the community (where it predicts admission rates and need for general practitioner visits) but has also been shown to have high predictive validity in the hospital environment (length of hospital stay, mortality in elderly wards, discharge destination in orthopaedic patients). ${ }^{8,21}$ Stratton et al. ${ }^{30}$ compared it with various other validated screening tools and found it as good as and faster than most (3-5 minutes).

The Mini Nutritional Assessment (MNA) was developed to evaluate the risk of malnutrition in the elderly in home-care programmes, nursing homes and hospitals. In theory it should be better at identifying frail elderly patients at risk of undernutrition since it encompasses physical and mental aspects of health; ${ }^{20,21,31}$ moreover, it detects risk of malnutrition at a time when albumin levels and BMI are still normal. ${ }^{32}$ The score for screening is derived from six components - reduced food intake in the preceding three months; weight loss during the preceding three months; mobility; psychological stress or acute disease in the preceding three months; neuropsychological problems; body mass index. ${ }^{20}$

The MNA has predictive validity for adverse health outcome, social functioning, mortality and rate of visits to the general practitioner as well as length of hospital stay, likelihood of discharge to a nursing home and mortality. ${ }^{20,21}$ A score of 11 or more on the screening component of the MNA offers strong evidence that malnutrition is absent. ${ }^{33}$ The MNA has also shown itself practical and reliable. ${ }^{19,21,34}$

\section{IS NUTRITIONAL INTERVENTION BENEFICIAL IN THOSE IDENTIFIED BY SCREENING?}

The above key question is made difficult to answer by the wide range of interventions, differences between populations studied and diversity of outcome measures. ${ }^{14,35,36}$ Most trials have used primary nutritional outcome measures such as weight change and dietary intake rather than mortality, morbidity and functional outcomes. ${ }^{14}$ On existing evidence, however, dietary supplementation does appear beneficial in terms of weight gain, arm muscle 
circumference, length of hospital stay and mortality. ${ }^{14,35-37}$ Weight gain is an outcome measure of particular importance since it correlates with improvements in immune function, muscle function and functional independence. ${ }^{36}$ In meta-analyses of the benefits of supplementation in elderly people at risk from malnutrition, a significantly reduced mortality is seen in the following groups: patients defined as undernourished; supplements of more than $400 \mathrm{kcal}$ per day; age over 75; supplements for more than 35 days; those acutely unwell; patients in hospital or nursing homes. ${ }^{7}$

Large multicentre randomized controlled trials are needed to assess the benefits of nutritional intervention in clearly defined patient groups. ${ }^{14,36}$ Evidence has been offered that nutritional support is cost-effective, particularly in terms of hospital and nursing care. ${ }^{38}$

\section{CONCLUSION}

The importance of nutrition is now specified in documents such as the UK National Service Framework for older people but there is no consensus on methods of detection. Anthropometry and biochemical markers have drawbacks, and the choice falls on 'screening tools' employing combinations that can be applied without specific skills or training.

In a particular hospital or community, there is much to be said for use of a single such tool, and one that attracts wide support is MUST, supported by the British Dietetic Association, the British Association for Parenteral and Enteral Nutrition, the Royal College of Nursing, the Registered Nursing Homes Association and the Royal College of Physicians.

\section{REFERENCES}

1 Stratton RJ, Green CJ, Elia M. Disease Related Malnutrition: an Evidence Based Approach to Treatment. Oxford: CABI, 2003

2 Klein S, Kinney J, Jeejebhoy K, et al. Nutrition support in clinical practice: review of published data and recommendations for future research directions. Am J Clin Nutr 1997;66:683-706

3 Azad N, Murphy J, Amos SS, Toppan J. Nutrition survey in an elderly population following admission to a tertiary care hospital. Can Med Assoc J 1999;161:511-15

4 Edington J. Problems of nutritional assessment in the community. Proc Nutr Soc 1999;58:47-51

5 Baker JP, Detsky AS, Wesson DE, et al. Nutritional assessment: a comparison of clinical judgement and objective measurements. N Engl J Med 1982;306:969-72

6 Alpers DH, Klein S. Approach to the patient requiring nutritional supplementation. In Yamada T, ed. Textbook of Gastroenterology, 4th edn. Baltimore: Lippincott Williams \& Wilkins, 2003
7 Milne AC, Potter J, Avenell A. Protein and energy supplementation in elderly people at risk from malnutrition. Cochrane Database of Systematic Reviews 2005, Issue 1, Art No.: CD003288.pub2

8 Elia M. (ed.) Screening for Malnutrition: A Multidisciplinary Responsibility. Development and use of the 'Malnutrition Universal Screening Tool' ('MUST') for Adults. BAPEN 2003

9 Meydani M. Nutrition interventions in aging and age-associated disease. Proc Nutr Soc 2002;61:165-71

10 Gariballa S. Nutrition and older people: special considerations relating to nutrition and ageing. Clin Med 2004;4:411-14

11 Gariballa SE, Sinclair AJ. Nutrition, ageing and ill health. Br J Clin Nutr 1998;80:7-23

12 Woo J. Nutrition in the elderly. J Hong Kong Geriatr Soc 2000;3: $15-18$

13 Kopelman P, Lennard-Jones J. Nutrition and patients: a doctor's responsibility. Clin Med J 2002;2:391-4

14 Leonard-Jones JE. A Positive Approach to Nutrition as Treatment. London: King's Fund, 1992

15 Whirter JP, Pennington CR. Incidence and recognition of malnutrition in hospital. BMJ 1994;308:945-8

16 Jeejeebhoy KN, Baker JP, Wolman SL, et al. Critical evaluation of the role of clinical assessment and body composition studies in patients with malnutrition and after total parenteral nutrition. Am J Clin Nutr 1982;35:1117-27

17 Balcombe NR, Ferry PG, Saweirs WM. Nutritional status and well being. Is there a relationship between body mass index and the wellbeing of older people? Curr Med Res Opin 2001;17:1-7

18 Muhlethaler R, Stuck AE, Minder CE, Frey BM. The prognostic significance of protein-energy malnutrition in geriatric patients. Age Ageing 2005;24:193-7

19 Davidson J, Getz M. Nutritional risk and body composition in freeliving elderly participating in congregate meal-site programs. $J$ Nutr Elderly 2004;24:53-68

20 Berner YN. Assessment tools for nutritional status in the elderly. IMAJ 2003;5:365-7

21 Knodrup J, Allison SP, Elia M, Vellas B, Plauth M. ESPEN guidelines for nutrition screening 2002. Clin Nutr 2003;22:415-21

22 Elia M, Stroud M. Nutrition in acute care. Clin Med 2004;4:405-7

23 Buzby GP, Mullen JL. Analysis of nutritional assessment indices: prognostic equations and cluster analysis. In: Heymesfield $S$, Wright R, eds. Nutritional Assessment. Oxford: Blackwell Scientific, 1984

24 World Health Organization. Obesity: Preventing and Managing the Global Epidemic. (WHO Tech Rep Ser 894). Geneva: WHO, 2000

25 McKinlay J. Nutritional assessment: identifying patients' needs. $J R$ Coll Physicians Edinb 2004;34:28-31

26 Campillo B, Paillaud E, Uzan I, et al. Value of body mass index in the detection of severe malnutrition: influence of the pathology and changes in anthropometric parameters. Clin Nutr 2002;23: 551-9

27 World Health Organization. Physical Status: the Use and Interpretation of Anthropometry. (WHO Tech Rep Ser 854). Geneva: WHO, 1995

28 Macallan D. Malnutrition and infection. Medicine 2005;33:3

29 Corish C, Kennedy NP. Anthropometric measurements from a cross sectional survey of Irish free-living elderly subjects with smoother centile curves. Br J Nutr 2003;89:137-45

30 Stratton RJ, Hackston A, Longmore D, et al. Malnutrition in hospital outpatients and inpatients: prevalence, concurrent validity and ease of use of the "Malnutrition Universal Screening Tool" ("MUST") for adults. Br J Nutr 2004;92:799-808

31 Salva A, Pera G. Nutrition and ageing: screening for malnutrition in dwelling elderly. Publ Health Nutr 2001;4:1375-8 
32 Guigoz Y, Lauque S, Vellas BJ. Identifying the elderly at risk for malnutrition. The Mini Nutritional Assessment. Clin Geriatr Med 2002; 18:737-57

33 Visvanathan R, Newbury JW, Chapman I. Malnutrition in older people. Aust Fam Physician 2004;33:799-805

34 Soini H, Routasalo P, Lagstrom H. Characteristics of the MiniNutritional Assessment in elderly home-care patients. Eur J Clin Nutr 2004;58:64-70

35 Cheskin LJ, Mitchell AM. Review: oral protein and energy supplements reduce all cause mortality in elderly people. Evid Based Med 2003;8:82
36 Potter J, Langhorne O, Roberts M. Routine protein energy supplementation in adults: systematic review. BMJ 1998;317:495-501

37 Payette H, Boutier V, Coulombe C, Gray-Donald K. Benefits of nutritional supplementation in free-living, frail, undernourished elderly people: a prospective randomized community trial. J Am Diet Assoc 2002; 102:1088-95

38 Armand-Battandier F, Malvy D, Jeandel C, et al. Use of oral supplements in malnourished elderly patients living in the community: a pharmaco-economic study. Clin Nutr 2004;23:1096-103 